\title{
Application of a Hydraulic and Pneumatic Transient Model to Investigate Pavement Heaving near a Large Diameter Sewer
}

\author{
Peter R. Klaver, ${ }^{1}$ Joshua Hallsten ${ }^{2}$ and Jon Bergenthal ${ }^{2}$ \\ ${ }^{1}$ LimnoTech, Ann Arbor, Michigan; ${ }^{2} J a c o b s$, St. Louis, Missouri.
}

\begin{abstract}
The sewer district serving a Midwestern United States city recently responded to an incident of pavement heaving associated with a drop structure feeding a large diameter combined sewer relief tunnel. The damage occurred following wet weather events where the relief sewer experienced rapid filling and surcharging. Repairs included the provision of a ventilation grate on a riser that had been sealed and paved over. An investigation was undertaken to determine the cause of the pavement heaving, and whether additional mitigation was warranted beyond the ventilation grate.

Pressurization of the air space in the sealed riser appeared to be the primary cause, and provision of ventilation was an adequate mitigation. However, the grate in the street raised the potential for air and water releases from trapped air pockets. Numerous scenarios were modeled to explore the possibility of trapping air pockets in the vicinity of the riser with the new grate. The risk of trapping air was shown to be low, owing largely to the abundant inflow near the upstream end of the sewer, which forcibly exhausts air at downstream locations ahead of any filling bores.
\end{abstract}

\section{Problem Statement}

The sewer district serving a Midwestern United States city recently responded to an incident of pavement heaving associated with a drop structure feeding a large diameter combined sewer relief tunnel. The damage occurred following wet weather events where the relief sewer experienced rapid filling and surcharging. Repairs included the provision of a ventilation grate on a riser that had been sealed and paved over. The cause of the pavement heaving was investigated to determine if additional mitigation was warranted beyond the ventilation grate.

The issue, as it presented itself, had the appearance of a pneumatic pressurization incident. Such incidents are occasionally reported in the literature, although their occurrence is likely more frequent than reporting would suggest. Structural damage following rapid pressurization of a storm sewer in Edmonton, Alberta was linked to pneumatic effects (City of Edmonton 1995) and investigated with numerical and physical modeling by Zhou et al. (2002). Later work by Wright (2013), Vasconcelos and Leite (2012) and Lewis (2011) extended our understanding of the role of air in the pressurization of rapidly filling storm water systems. Klaver et al. (2016) used a numerical model for rapid filling that included air pressurization effects and, following a wet weather event in Portland, Oregon, they concluded that pressurized air in a sealed access point riser was responsible for damage to the riser structure and the surrounding asphalt pavement. Based on this work, a similar approach was adopted to assess the extent to which air pressurization was responsible for the current problem.

\section{Study Approach}

A numerical model of the system was developed using the SHAFT-Air framework, which is a one-dimensional finite volume model designed specifically for rapidly varied mixed flow systems. Inflows to the system were produced by a collection system model, using rainfall data collected during the modeled events. The model was used to simulate the two rain events when pavement heaving was observed. Although the model predictions could not be directly verified, as no observed data were available from the events, the presence of transient hydraulic and pneumatic effects in the results was taken as sufficient evidence that such forces played a significant role in the observed pavement damage.

The numerical basis of SHAFT has been fully documented elsewhere (Vasconcelos et al. 2006). The model is based on the 1-D Saint-Venant equations written in conservative form and discretized over a finite volume framework. The state variables are defined at cell centres and the fluxes are defined at cell interfaces. The resulting Reimann problem is solved by Roe's method (Macchione and Morelli 2003). Transitions between free surface and pressurized flow are handled using the two-component pressure approach (Vasconcelos et al. 2006). The modeling approach compared well with other transient flow solvers (Vasconcelos and Wright 2007). SHAFT has been used to evaluate transient issues

Klaver, Peter R., Joshua Hallsten and Jon Bergenthal. Application of a Hydraulic and Pneumatic Transient Model to Investigate Pavement Heaving near a Large Diameter Sewer. Journal of Water Management Modeling 27: C462. doi: 10.14796/JWMM.C462.

(c) CHI 2019. www.chijournal.org ISSN 2292-6062. 
in the design of storage tunnels in Washington, DC and London, England (Lautenbach et al. 2010). An extension to SHAFT that simulates air pressurization in riser structures was described by Klaver et al. (2016).

\section{Model Development}

The SHAFT model requires the system geometry of the domain of interest and the associated inflows for particular events. When applying the model to a sewage storage tunnel, the upstream and downstream boundaries of the model are typically defined by the linear extent of the tunnel. As this application represented only a portion of a larger sewer system, the boundaries were selected such that the transient phenomena of interest could be completely captured by the model. In addition, downstream boundary conditions that related water surface elevation and discharge were also required to account for flow leaving the system. The following sections describe the development of the system geometry, the inflow hydrographs and the downstream boundary conditions.

\subsection{System Geometry}

The SHAFT model geometry for the combined system relief sewer was derived from a SWMM-based model of the larger basin, supplemented by as-built construction drawings, inspection reports and photographs. Additional information on the operation of various control gates in the system was supplied by operations personnel.

The basic configuration of the model consisted of the following features, which are shown in Figure 1:

approximately $6.1 \mathrm{~km}$ of $5.0 \mathrm{~m}$ diameter basket handle sewer beginning near the location of the pavement heaving and extending to outfall BP-015 at the river;

approximately $0.6 \mathrm{~km}$ of $4.0 \mathrm{~m}$ diameter basket handle sewer extending upstream from the location of the pavement heaving;

approximately $1.0 \mathrm{~km}$ of $4.4 \mathrm{~m}$ diameter circular sewer beginning at the diversion dam at station $32+00$ on the main relief sewer, and extending to outfall BP-014 at the river;

a short section of $5.0 \mathrm{~m}$ horseshoe sewer connecting a drop shaft near the location of pavement heaving to the relief sewer;

a pair of $5.0 \mathrm{~m}$ by $2.0 \mathrm{~m}$ slide gates just upstream of the outfall BP-015; and

a $4.4 \mathrm{~m}$ flap gate about $0.9 \mathrm{~km}$ upstream of the outfall BP-014.

A typical cross sectional profile of the baskethandle sewer is shown in an inset in Figure 1.The system also includes a second pair of slide gates on the $5.0 \mathrm{~m}$ basket handle sewer $\sim 0.9 \mathrm{~km}$ upstream of the outfall. These gates were not included in the model, however, because they remained open throughout the modeled events. The operation of the outfall gates was simulated using a variable area orifice boundary condition. A fully dynamic simulation of unsteady flap gate operation has not been implemented in SHAFT, so a rating curve approach was used to simulate losses in the forward direction, while preventing any flow in the reverse direction.

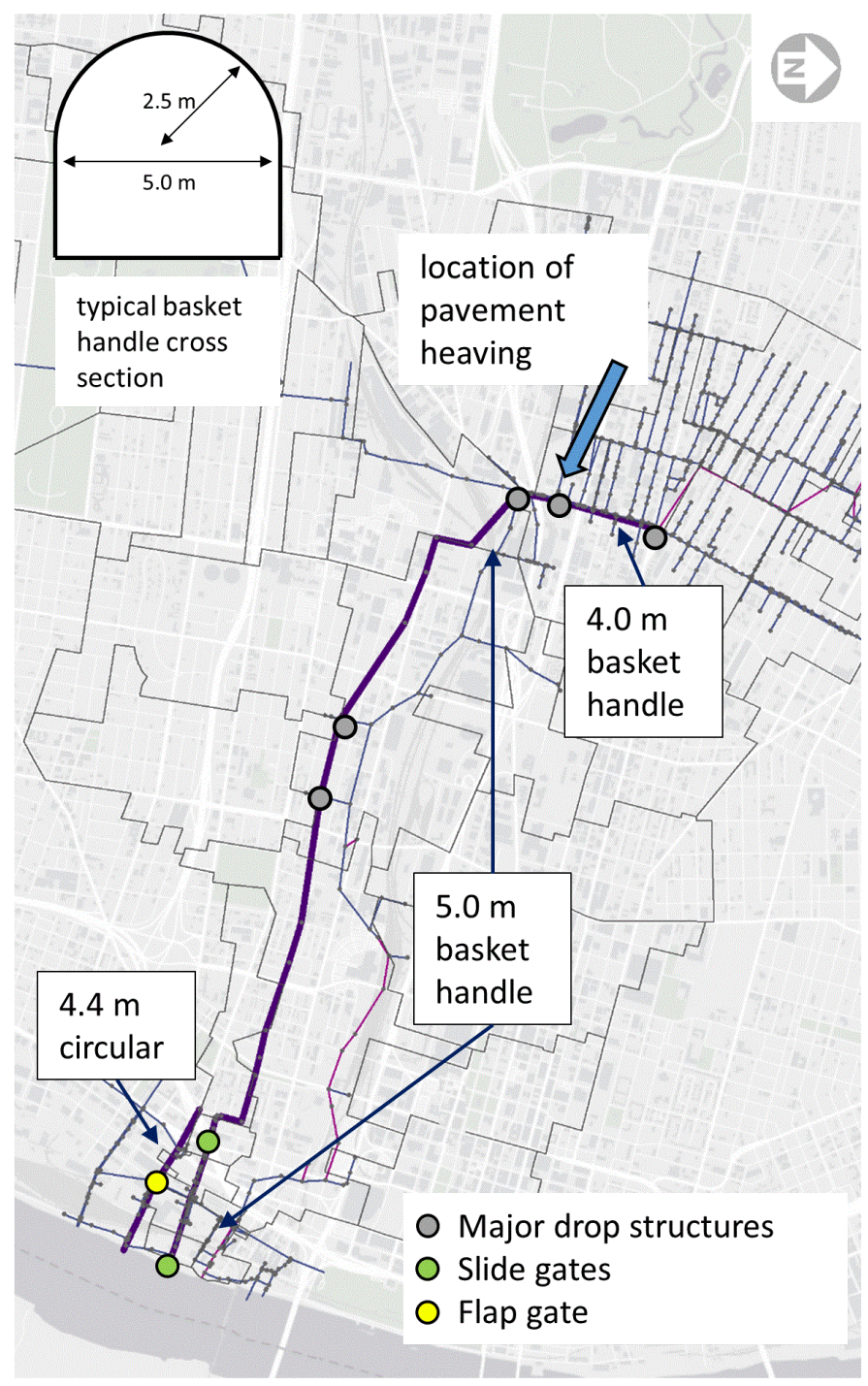

Figure 1 Study area.

The upstream boundary was chosen to be a sufficient distance from the location of pavement heaving so that any transient wave reflected from these boundaries would not have a significant influence on hydraulic conditions at points of interest. The downstream boundaries were defined by the river outfalls of the basket handle (BP-015) and circular sewers (BP-014) and they were treated as time-varying fixed stage elevations. An open radiation boundary has not been developed for SHAFT at this time, which means that gravity waves will be reflected by river stage. Although this is not physically realistic, the height of the outgoing waves in the simulations was not excessive and the modeling results were not compromised. 
The combined relief sewer also has a diversion to an interceptor tunnel near station 14+00. This was not included in the model, however, as it was assumed that surcharging of the interceptor would result in only minimal wet weather flow being diverted from the relief sewer. Instead, all discharge from the model takes place through the two outfalls, in proportions that vary depending on gate operation.

The representation of the relief sewers in SHAFT consisted of an interconnected series of 20 junctions and 16 reaches, which are listed in Table 1 and Table 2. A schematic of these junctions and reaches is shown in Figure 2, which also shows the locations of inflows and rating curve connections, which are described in more detail below.

Table 1 Junction geometry for SHAFT model.

\begin{tabular}{clcc}
\hline ID & \multicolumn{1}{c}{ Junction Name } & Invert Elevation $(\mathrm{m})^{1}$ & Junction Area $\left(\mathrm{m}^{2}\right)$ \\
\hline 1 & GW16A-1\&2 & 118.37 & 25.3 \\
2 & 21D4-036C & 117.17 & 25.3 \\
3 & Drop Shaft A & 118.37 & 25.3 \\
4 & 21D1-643C & 118.37 & 25.3 \\
5 & 21D1-053C & 118.57 & 25.3 \\
6 & Drop Shaft B & 118.57 & 25.3 \\
7 & Drop ShaftC & 118.57 & 25.3 \\
8 & 20F2-200C & 118.46 & 25.3 \\
9 & Drop Shaft D & 118.47 & 25.3 \\
10 & 20F1-010C & 118.47 & 0.0 \\
11 & Drop Shaft E & 119.01 & 15.7 \\
12 & 21D4-036Ca & 118.37 & 25.3 \\
13 & BP-015 & 118.37 & 25.3 \\
14 & 21D1-643Ca & 117.98 & 15.3 \\
15 & 21D4-057C & 117.16 & 15.3 \\
16 & Flap Gate & 117.16 & 15.3 \\
17 & MC20 & 116.61 & 15.3 \\
18 & BP-014 & 115.85 & 15.3 \\
19 & Drop ShaftF & 118.47 & 19.9 \\
20 & 20F1-005C & 118.47 & 1.82 \\
\hline
\end{tabular}

'All elevations given in NAVD 88.

Table 2 Reach geometry for SHAFT model.

\begin{tabular}{llclcccc}
\hline ID & $\begin{array}{r}\text { Upstream } \\
\text { Junction }\end{array}$ & $\begin{array}{c}\text { US Elev. } \\
(\mathrm{m})^{1}\end{array}$ & $\begin{array}{c}\text { Downstream } \\
\text { Junction }\end{array}$ & $\begin{array}{c}\text { DS Elev. } \\
(\mathrm{m})^{1}\end{array}$ & $\begin{array}{c}\text { Length } \\
(\mathrm{m})\end{array}$ & $\begin{array}{c}\text { Slope } \\
(\%)\end{array}$ & $\begin{array}{c}\text { Depth } \\
(\mathrm{m})^{2}\end{array}$ \\
\hline 1 & 21D4-036Ca & 118.37 & GW16A-1\&2 & 118.37 & 485 & 0.00 & 5.03 \\
2 & Drop Shaft A & 118.37 & 21D4-036C & 118.37 & 143.4 & 0.00 & 5.03 \\
3 & 21D1-643C & 118.37 & Drop Shaft A & 118.37 & 367 & 0.00 & 5.03 \\
4 & 21D1-053C & 118.57 & 21D1-643C & 118.57 & 131.1 & 0.00 & 5.03 \\
5 & Drop Shaft B & 118.57 & 21D1-053C & 118.57 & 2113 & 0.00 & 5.03 \\
6 & Drop ShaftC & 118.57 & Drop Shaft B & 118.57 & 549 & 0.00 & 5.03 \\
7 & 20F2-200C & 118.57 & Drop ShaftC & 118.57 & 1723 & 0.00 & 5.03 \\
8 & Drop Shaft D & 118.47 & 20F2-200C & 118.46 & 442 & 0.00 & 5.03 \\
9 & 20F1-010C & 118.47 & Drop Shaft D & 118.47 & 245 & 0.00 & 5.03 \\
10 & Drop ShaftE & 119.01 & 20F1-005C & 118.48 & 660 & 0.08 & 3.96 \\
11 & GW16A-1\&2 & 118.37 & BP-015 & 118.37 & 60.0 & 0.00 & 5.03 \\
12 & 21D1-643Ca & 117.98 & 21D4-057C & 117.16 & 410 & 0.20 & 4.27 \\
13 & Flap Gate & 117.16 & MC20 & 116.61 & 272 & 0.20 & 4.27 \\
14 & MC20 & 116.61 & BP-014 & 115.85 & 425 & 0.18 & 4.42 \\
15 & Drop Shaft F & 118.47 & 20F1-010C & 118.47 & 15.24 & 0.00 & 5.03 \\
16 & 20F1-005C & 118.47 & 20F1-010C & 118.47 & 12.19 & 0.00 & 3.96 \\
\hline 1All elevations given in NAVD 88; & & & & &
\end{tabular}

${ }^{\top}$ All elevations given in NAVD 88;

${ }^{2}$ All cross sections are modified basket handle, except reach 14 which is circular.

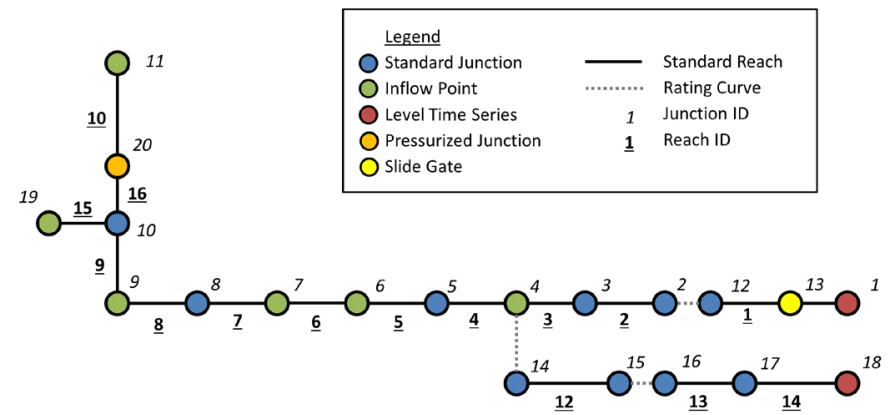

Figure 2 Model schematic.

\subsection{Inflow Hydrographs and Level Boundaries}

Boundary condition forcing functions for the SHAFT model consist of flow hydrographs, which are introduced at model junctions, and water surface level time series that are imposed at the furthest downstream junctions of the two branches. The flow hydrographs for the model were derived from an XP-SWMM model of the larger sewer basin, and the level time series were derived from data from a USGS gauge at a location near the two outfalls. Additional details on the development of these conditions are provided below.

\section{Inflow Hydrographs}

The original pavement damage was believed to have occurred during a rain event on 2016-08-14; the second event took place on 2016-09-09-10. A total of six junctions in the SHAFT model received inflow derived from the collection system model, which was driven by radar rainfall data; these junctions are identified in Figure 2. A general idea of the inflow pattern of each storm can be obtained from Figures 3 and 4, which present composite inflow hydrographs (i.e. step-by-step summation of all six individual hydrographs) and cumulative inflow volumes for the two events modeled.

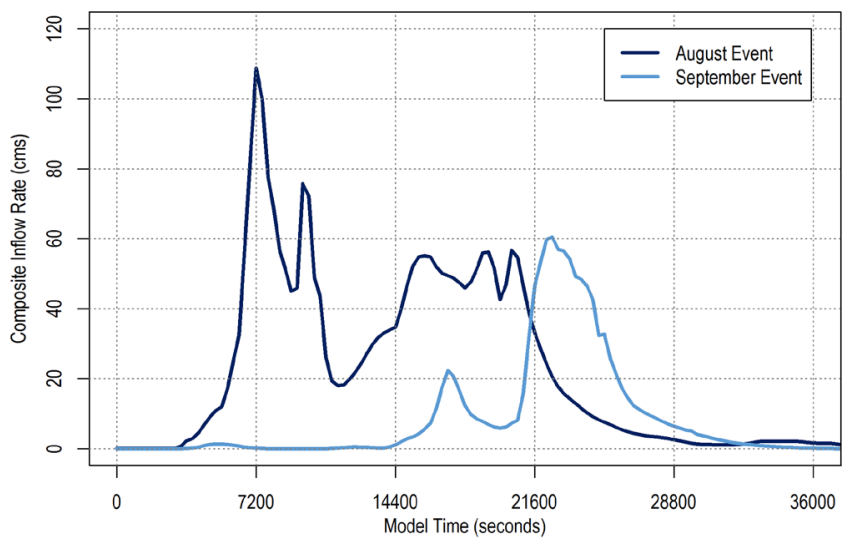

Figure 3 Composite inflow hydrographs for modeled events. 


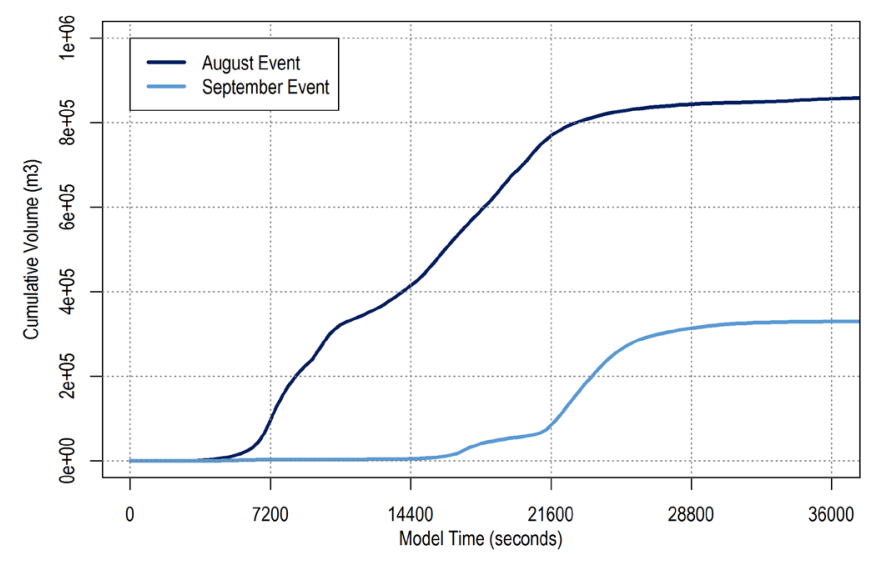

Figure 4 Cumulative inflow volumes for modeled events.

\section{Level Time Series Boundaries}

The SHAFT model has two junctions from which flow may leave the system, corresponding to the river outfalls of the basket handle (BP-015) and circular (BP-014) sewers. These boundaries were treated as a known water surface elevation, defined by the stage of the river. The stage data, at $1 \mathrm{~h}$ resolution, were downloaded via the NWIS and converted to elevation using the published gauge datum. Although the two outfalls are downstream of the USGS gauge, and thus at a lower water surface elevation, the difference was estimated to be in the order of inches and no correction was made to the time series.

The simulation period for the August event began on 201608-14 at 24:00 $\mathrm{h}$ and ran for $4 \mathrm{~h}$. Over this period, the river level ranged from $120.2 \mathrm{~m}$ to $120.4 \mathrm{~m}$ (NAVD 88). The average river stage for the entire day was $5.0 \mathrm{~m}$ (120.7 m, NAVD 88), which represents a $6 \%$ exceedance level for the month of August. The simulation period for the September event ran from 2016-09-09 20:00 $\mathrm{h}$ to 2016-09-10 08:00 h, over which time the river level steadily increased from $120.3 \mathrm{~m}$ to $121.0 \mathrm{~m}$ (NAVD 88). The average stages for 2016-09-09 and 2016-09-10 were $4.6 \mathrm{~m}$ (120.3 m, NAVD 88) and $5.5 \mathrm{~m}$ (121.2 m, NAVD 88). These represent exceedance levels of $8.8 \%$ and $5.4 \%$ for the month of September.

The return period for the river stage during the August event is $\sim 16 \mathrm{y}$, whereas for the two days of the September event the return periods are $\sim 11 \mathrm{y}$ and $\sim 18 \mathrm{y}$. While these are relatively low frequencies, the importance of river stage in contributing to the observed events was not assumed; instead, it was tested by running the models using lower stage levels as boundary conditions.

\section{Slide Gate Boundaries}

There are two locations in the basket handle sewer where slide gates can affect flow conditions. Operations staff were interviewed concerning the operation of these gates to determine whether they needed to be included in the model. Control gates D16B-1 and D16B-2 are in the basket handle sewer $12 \mathrm{~m}$ downstream of the diversion to the circular sewer. These gates close when the river elevation is $>122.2 \mathrm{~m}$ and reopen when the river elevation becomes $<121.9 \mathrm{~m}$. As the river levels were never this high during either of the modeled events, these gates were not included in the model as they would always have been open.

There is a second pair of gates, GW16A-1 and GW16A-2, at the outfall to the river. These gates are controlled by both the river level and the level in the basket handle sewer, measured at control gates D16B-1 and D16B-2. The gates close when the river level is $>119.2 \mathrm{~m}$ to prevent excessive sedimentation in the basket handle sewer. If the level at the upstream gates rises to $>1 \mathrm{~m}$ above the river level, however, the gates move to $50 \%$ open, which takes $5 \mathrm{~min}$. If, after $30 \mathrm{~min}$, the upstream level is $\geq 1$ $\mathrm{m}$ above the river level, the gates take another $5 \mathrm{~min}$ to become fully open. If sewer level is $<1 \mathrm{~m}$ below river level, the gates take 5 min to fully close; that is, after 35 min the gates are fully open or fully closed.

The operating rules for GW16A-1 and GW16A-2 are not explicitly coded in the SHAFT model. The model does, however, permit gate movement to be defined by a time series. Some simple trials were conducted to determine when the gate movement would occur in each of the two events, and suitable time series were developed; these are shown in Figure 5. Note that for each event, the gate was initially closed.

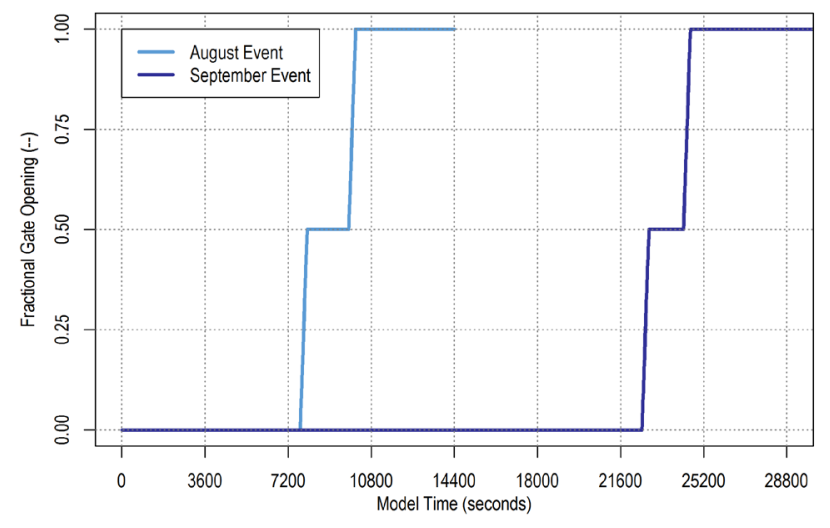

Figure 5 Time series for gates GW16A-1 and GW16A-2 positions for modeled events.

\section{Rating Curve Boundaries}

As shown in Figure 2 there are three internal boundary conditions defined by rating curves. The approach taken was to develop two-dimensional lookup tables that represented families of curves to handle both free discharge and backwater conditions. Each table has one curve that relates discharge to depth for freely discharging conditions, and additional curves relate discharge to differential head for various tail water depths.

The first rating curve represents the weir in the basket handle sewer just downstream from the diversion to the interceptor, at station $13+94$. The second curve represents the weir diversion to the circular sewer at station $32+00$. The third rating curve represents the flap gate at station $22+66$ on the circular sewer. The 
behaviour of the gate in unsteady flow was not modeled explicitly; instead, the curves were set up to provide nominal head loss in the forward direction and no flow in the reverse direction, the latter case being deemed the most important feature to include in the model. Given the distance between the flap gate and the area of pavement heaving ( $5.6 \mathrm{~km})$, this approximation was considered to have negligible effect on conditions in the area of interest.

\section{Modeling Results}

This section discusses the results of the event modeling using the SHAFT model. In neither of the two events modelled did filling patterns indicate that pockets of air were trapped in the basket handle or the circular sewers, nor were conditions that suggested air-water releases (geysers) simulated. However, pressurization of the air space in the sealed riser on the basket handle sewer was simulated to an extent that can be reasonably expected to cause or contribute to the pavement heaving observed. The SHAFT model also provided some insights into the develop-ment of filling bores in the basket handle sewer, which may have implications for transient phenomena in other parts of the system, although we note that these have not been consistently documented. These model results are discussed in greater detail for individual events in the following sections.

\subsection{Air Pressurization}

The air space in the sealed riser (structure 20F1-005C) was modeled as being completely sealed, with no ventilation. Although it is likely that air would be able to escape into the overlying soils, the process would be difficult to quantify and the assumption of zero venting was considered to be a reasonable approximation. The hydraulic grade line elevation (HGL) and gauge pressure, once surcharged, for the August, 2016 event are shown in Figure 6. There are two peaks corresponding to two periods of rainfall in the event. The largest occurs during the second period of rainfall, where HGL reaches $129.2 \mathrm{~m}$ and the gauge pressure reaches $54 \mathrm{kPa}$.

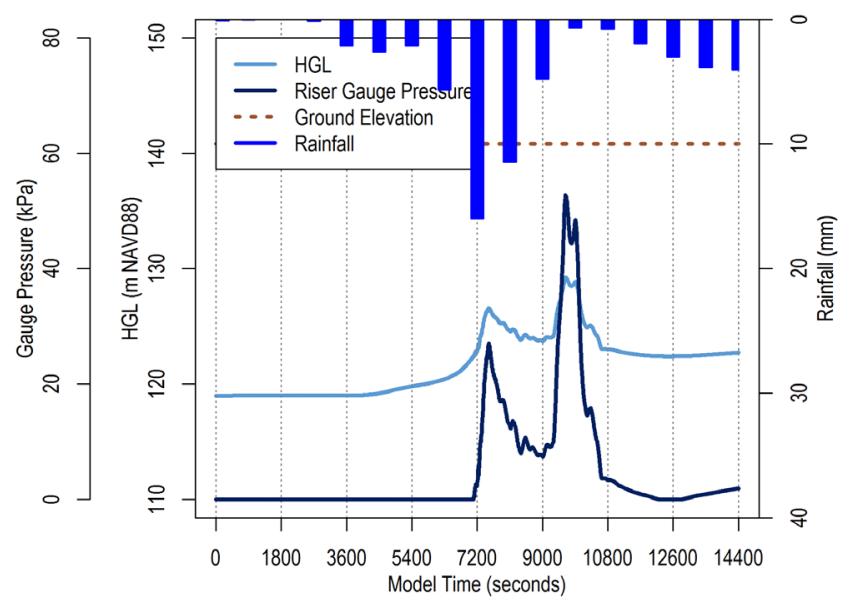

Figure 6 HGL elevation and headspace pressure in sealed riser for August, 2016 event.
The $1.5 \mathrm{~m}$ diameter riser is capped by a $1.2 \mathrm{~m}$ square transition section. To calculate the pressure on the slab on top of the transition, an area of $1.44 \mathrm{~m}^{2}$ was used. The peak modeled pressure in the August event was $77800 \mathrm{~N}$. Although this result is based on the assumption of zero ventilation, and thus may be somewhat greater than would occur when air is allowed to escape into soil voids, the magnitude of the force is considerable and may be taken as evidence that pressurization has the potential to lift the structure to an extent capable of disrupting the pavement. Given that the circumstances leading to the surcharge condition occur frequently, pressurization of the riser likely occurs relatively often, and it is plausible to expect, over time, the repeated action to lift the transition structure to the extent observed after the structure was exposed by operations staff following the August rain event.

Figure 7 shows HGL and gauge pressure in the riser for the September event, which occurred shortly after the structure was covered again. The rainfall was less than for the August event, leading to a lower maximum HGL elevation and a peak pressure of $16.5 \mathrm{kPa}$; the resulting force was calculated to be $23800 \mathrm{~N}$, using the same approach as for the August event. Although it was substantially less than in the August event, this force could also conceivably move the slab, especially when the reduced degree of compaction of the overburden immediately following the repair work is considered.

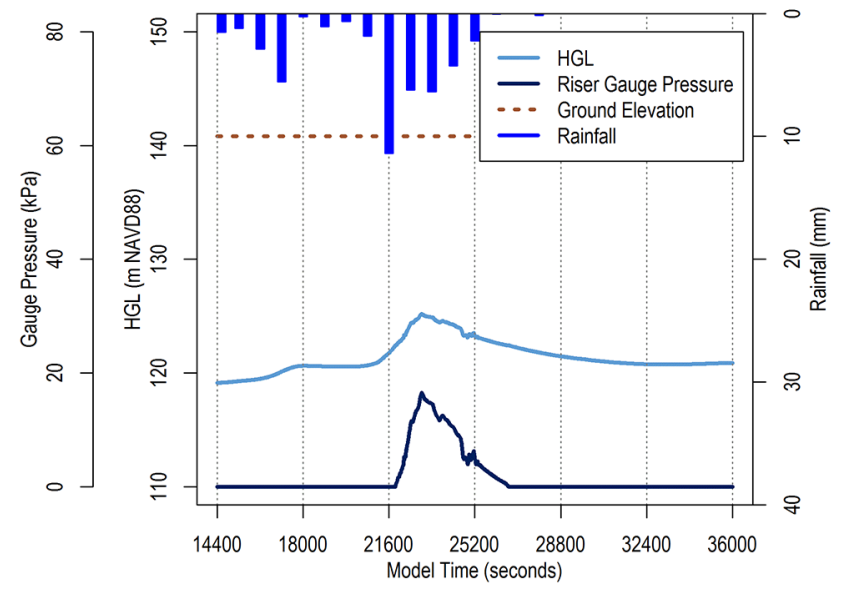

Figure 7 HGL elevation and headspace pressure in sealed riser for September, 2016 event.

After the September event, operations staff replaced the solid slab with one containing a grate. The available ventilation area relative to the riser cross section area appears to maintain only minimal pressurization during events, which was confirmed by running the SHAFT model with an estimated open ventilation area of $10 \%$ of the riser area. The results of these simulations are shown in Figure 8 and Figure 9, which show that the riser pressure is negligible. The figures also include the HGL from the pressurized runs for comparison; the increase in $\mathrm{HGL}$ for the ventilated simulations is essentially equivalent to the pressure head reduction from venting. We note that although the grate is likely 
sufficient to mitigate pressurization, it does not address the possibility of geyser-like releases of air and water mixtures from this location. This possibiity is discussed further in the next section.

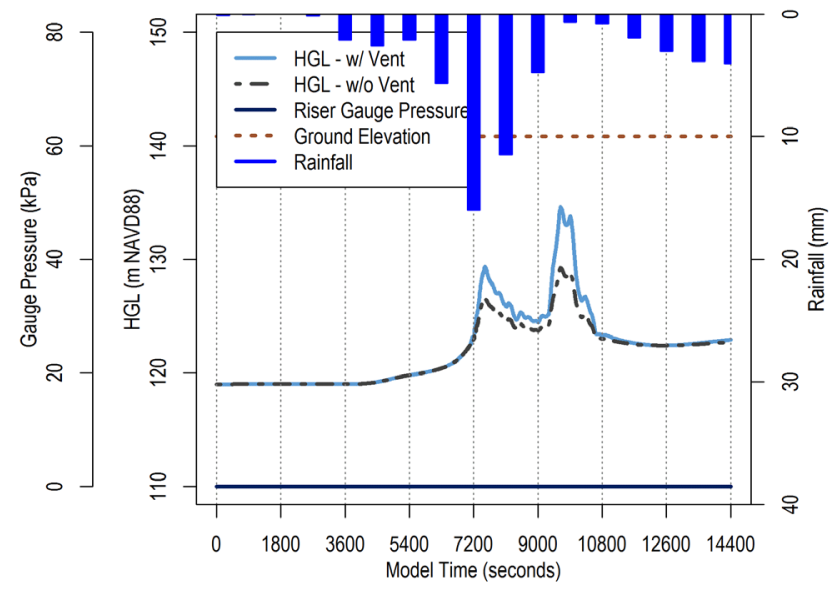

Figure 8 HGL elevation and headspace pressure in ventilated riser for August, 2016 event.

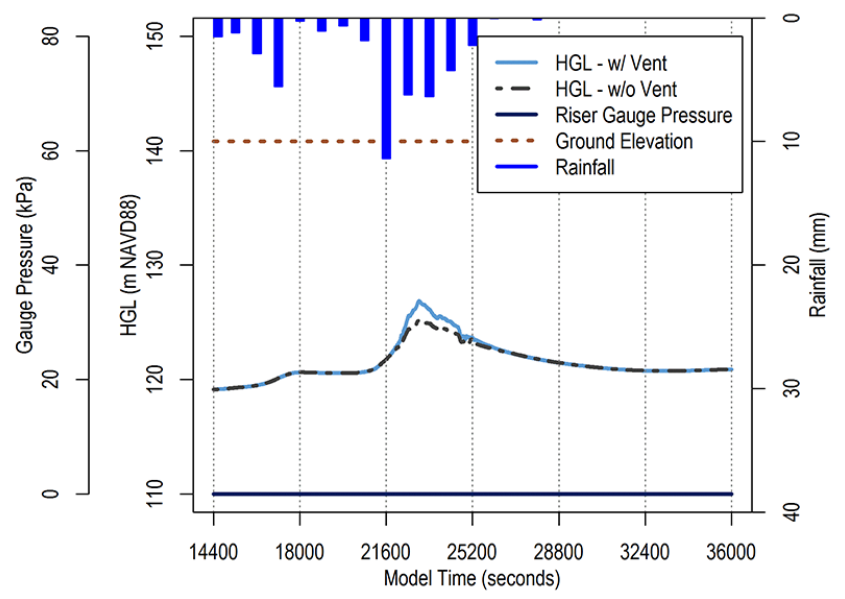

Figure 9 HGL elevation and headspace pressure in ventilated riser for September, 2016 event.

\subsection{Bore Movement and Air Pocket Trapping}

The SHAFT model permits the simulation of free surface discontinuities such as open channel and pressurized hydraulic bores. This capability is useful for the present application in determining conditions under which air pockets may become trapped during rapid filling, thus presenting geyser risks in addition to hydraulic surge issues. The profiles calculated for the August event are examined here, and the implications for air pocket trapping are discussed.

Figure 10 presents a series of four HGL snapshots from various times during the August rain event, which was characterized by two periods of rainfall, the second being more intense than the first.
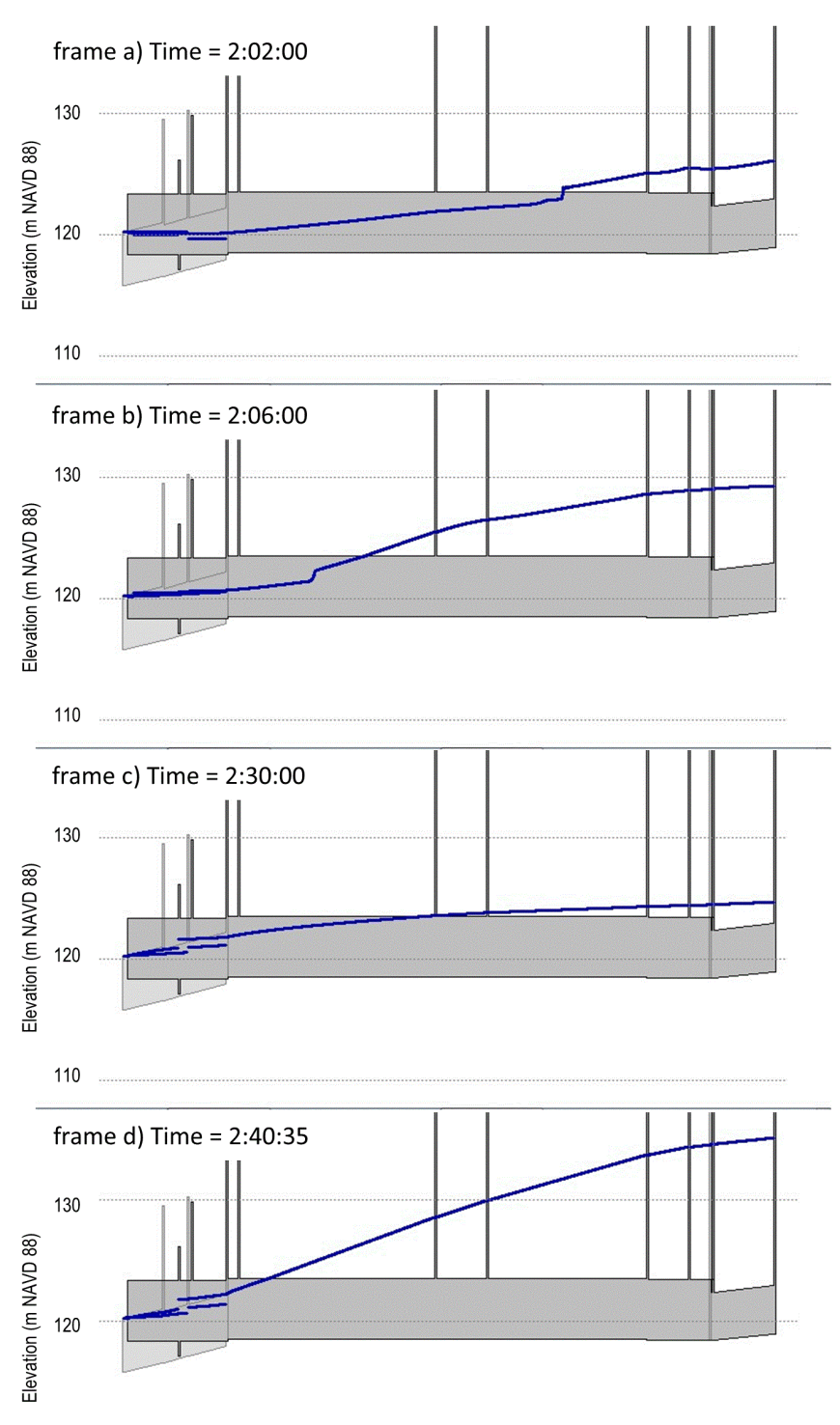

110

Figure 10 HGL profiles in basket handle sewer and circular sewer at various times during August, 2016 event.

Frame a in Figure 10 shows HGL at 2:02:00 h after the beginning of the simulation. The sealed riser structure is already surcharged, and a pressurized bore has developed about halfway between drop shaft $C$ and drop shaft $D$. No flow is leaving the system at this point because the water surface elevation in the basket handle sewer at the control point is not high enough to trigger the opening of the outfall gates; nor is the elevation high enough in the circular sewer to open the flap gate. The rapid increase in inflow to the upstream reaches of the basket handle sewer surcharges the system locally because the conveyance capacity of the sewer is low, owing to its flat slope.

In frame b, at 2:06:00 h, HGL at the sealed riser has reached the first peak of the event and the pressurized bore has become an open channel bore, owing to the decrease in inflow rate. 
Flow is just beginning to leave the system via the circular sewer although the gates at BP-015 have not yet begun to open. Air being exhausted from the basket handle sewer ahead of the flow regime transition appears to have several unobstructed paths by which to vent the sewer.

Frame $c$ shows HGL just before the second round of rainfall, after inflows have temporarily subsided. The gates at BP-015 are $50 \%$ open and flow is leaving the system at a rate of $\sim 44 \mathrm{~m}^{3} / \mathrm{s}$, split roughly $50 \%-50 \%$ between the two outfalls. Inflows from upstream areas, however, are $<44 \mathrm{~m}^{3} / \mathrm{s}$ and the basket handle sewer is emptying as a result.

Frame $d$ shows HGL at the time of the second, and larger, peak pressurization in the sealed riser. The basket handle sewer is in surcharge nearly all the way downstream to the circular sewer diversion, and the gates at BP-015 are about to completely open. For a brief time the circular sewer is completely surcharged, although the downstream end of the basket handle sewer remains in free surface mode. Levels begin to decrease shortly thereafter.

The behaviour of the basket handle sewer in terms of transition between open channel and pressure flow, and of air exhaust, is generally favourable with regard to the risk of trapping pockets of air in upstream reaches. Large diameter sewers that are closed at their downstream end, such as those typically designed for storage, may encounter a situation where inflow from the upstream end is in free surface flow until it reaches the downstream end, where the absence of any outflow results in a bore that propagates in the upstream direction; this situation has the potential to trap pockets of air near the upstream end, after the bore is reflected back downstream again. In the basket handle sewer, however, both the flat slope and the presence of at least one downstream outlet work together to maintain free surface flow at the downstream end while the upstream end becomes fully surcharged, and under these conditions there is virtually no opportunity for air to become trapped along the sewer crown anywhere in the vicinity of the now-ventilated riser structure, which is close to drop shaft $\mathrm{F}$.

A model run was also conducted using the August inflows, but with downstream conditions representing a river flood elevation of $128.5 \mathrm{~m}$, when the gates in the basket handle sewer would be closed, leaving only BP-014 as an outlet. The resulting grade line was higher at peak inflow conditions, as would be expected, but no air pocket entrapment was simulated by the model.

In a hypothetical event where all the inflow to the basket handle sewer would be from centrally located drop shafts and none from drop shaft $F$ or other points upstream, air would need to be exhausted from upstream locations ahead of inflows moving upstream in the flat sewer, and this scenario could result in trapping air pockets near drop shaft F. Simulations were carried out that increased inflow at downstream locations and reduced inflow at upstream locations in an effort to establish bores moving upstream that could result in trapped air pockets. However, the tributary area of the lower drop shafts (A through $D$ ) is small relative to the upstream locations, and it was not possible to trap air pockets in the upstream reaches of the sewer even with simulated inflows that likely exceeded the capacity of the drop shafts.

Finally, we note that the crown elevation in the $4.0 \mathrm{~m}$ basket handle sewer where the riser is located is $1.0 \mathrm{~m}$ lower than the $5.0 \mathrm{~m}$ basket handle sewer downstream. Even if trapped air were to travel along the crown of the larger sewer, it is doubtful that any significant volume could continue up the smaller sewer to the riser structure; instead, it would escape via drop shaft F. The lack of reported instances of this phenomenon may be taken as indirect confirmation of the low risk of such air releases.

\subsection{Effect of River Stage on Riser Pressurization}

The importance of river stage in influencing the pressurization of the riser was examined by running the model for both events at various river levels. In addition to the stage values during the actual events, which represented low-frequency conditions, the model was run using median (or 50\% exceedance levels for August and September) and at higher stages up to the flood stage of $128.5 \mathrm{~m}$. A summary of the stages used, along with their exceedance levels, is given in Table 3. Simulations were conducted both with the gate at BP-015 operating and with it inoperable so that the only outlet for the system was BP-014. Note that for river stages above $122.2 \mathrm{~m}$ the internal gates D16B-1 and D16B-2 will be closed, making BP-014 the only outlet; thus $121.9 \mathrm{~m}$ was the highest river stage used for gate operation simulations.

Table 3 River Stage and Exceedance Levels for Model Runs.

\begin{tabular}{cccc}
\hline \multicolumn{2}{c}{ August Event } & \multicolumn{2}{c}{ September Event } \\
Elevation (m, NAVD 88) & Exceedance $\%$ & Elevation (m, NAVD 88) & Exceedance \% \\
\hline 117.83 & $50 \%$ & 117.28 & $50 \%$ \\
120.28 & $8.9 \%$ & 120.62 & $7.4 \%$ \\
121.92 & $2.6 \%$ & 121.92 & $3.8 \%$ \\
123.44 & $1.7 \%$ & 123.44 & $2.4 \%$ \\
125.73 & $1.2 \%$ & 125.73 & $0.5 \%$ \\
128.47 & $0.5 \%$ & 128.47 & $<0.5 \%$ \\
129.54 & $<0.5 \%$ & 129.54 & $<0.5 \%$ \\
\hline
\end{tabular}

The maximum gauge pressure at the riser is shown in Figure 11 for each of the simulations. Although river stage clearly plays a role in the pressurization in the riser, it does not appear to be significant until relatively high levels are reached. The difference in maximum pressure between the $50 \%$ exceedance levels (the leftmost points on the plot) and the levels during the events, which were $<10 \%$ exceedance, is in the order of $\leq 7 \mathrm{kPa}$. The intensity of the inflow appears to be more important, based on the difference between the August and September events. Also significant is the overall conveyance capacity to the river; as shown by the August Event, No Gate Operation line in Figure 11; pressurization is significant even at the $50 \%$ exceedance stage if the gates at BP-015 are inoperable. This suggests that there may be benefit in maintaining the operating status of both gates at BP-015, to provide as much conveyance capacity as possible for large flows. 


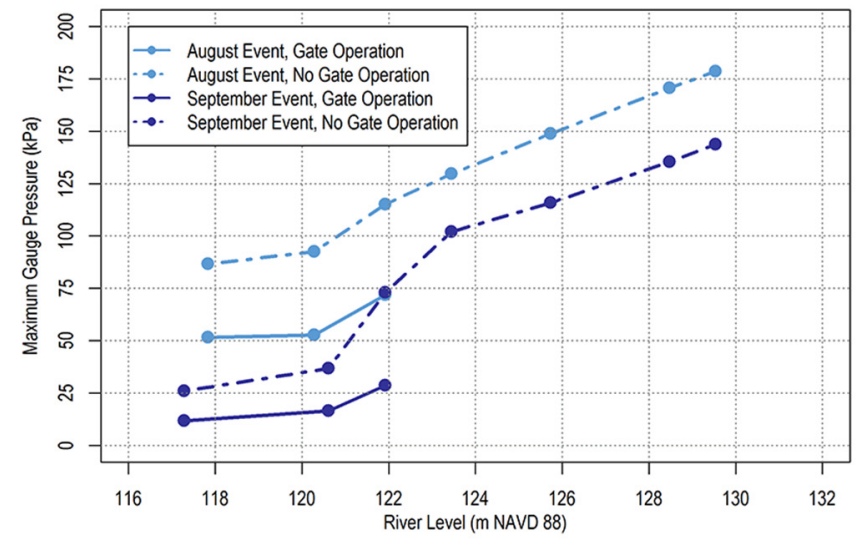

Figure 11 Summary of maximum gauge pressures at riser for simulations at different river stages.

\section{Conclusions}

The SHAFT framework was used to develop a model of a large relief sewer system. The model was run using boundary conditions, derived from information of actual system conditions, during which certain transient and pneumatic phenomena were either observed or presumed to occur. The model results can be reasonably interpreted to explain the observed events in terms of the imposed boundary conditions; that is, inflows to the collection system and gate operations at the downstream end. Specific conclusions regarding the observed events are:

1. Lack of ventilation for the $1.5 \mathrm{~m}$ diameter riser on the basket handle sewer, structure 20F1-005C, leads to pressurization of the air space in the riser. Pressures as high as $54 \mathrm{kPa}$ were simulated, resulting in forces of $77800 \mathrm{~N}$ on the $1.2 \mathrm{~m}$ square slab atop the riser for the August, 2016 event. This appears to be a likely cause of the pavement heaving that was observed above the 20F1-005C structure following the August, 2016 event.

2. The initial repair to the pavement above 20F1-005C did not provide additional ventilation, so that the subsequent event in September also led to pressurization. The modeled force in this event was $23800 \mathrm{~N}$, which, although less than the August event, may still have been enough to move the pavement, considering that the compaction of the fill material was likely less than before the repair project.

3. The installation of a ventilation grate above 20F1005C following the second event in September appears to be an adequate mitigation of the pressurization issues at this location.

4. The air in the riser was, from the model's perspective, present at the beginning of the rainfall event rather than introduced to the system via either forced convection at drop structures or deaeration of entrained air. While such additional air is clearly not helpful in a situation where ventilation is inadequate for any reason, it is important to note that the system is capable of pressurizing to a high level even with only ambient air.

5. The modeled conditions leading to the pressurization are not particularly rare, which raises the question as to why the observed pavement damage has not occurred more frequently. Given that the concrete transition slab on top of the riser showed a gap of nearly $15 \mathrm{~cm}$, it is unlikely that the situation was the result of a single event; rather, gradual movement as the result of repeated events appears to be a more plausible explanation. The visible buckling of the pavement may only have occurred after a certain threshold of displacement was reached. Moreover, we note that the riser was originally intended to be vented, and that the length of time it has been paved over is unknown.

\section{References}

City of Edmonton. 1995. A Report on the July 4, 1995 Storm Event. Edmonton, Alberta:Transportation Department, City of Edmonton.

Klaver, P. R., D. Collins, K. Robinson and S. Bell. 2016. “Modeling of Transient Pneumatic Events in a Combined Sewer Overflow Storage Tunnel System." Journal of Water Management Modeling 24: C409. doi: 10.14796/JWMM.C409.

Lautenbach, D. H., J. K. Marr, P. R. Klaver, J. F. Cassidy and D. Crawford. 2010. "A Tale of Two Capitals: Modeling Helps Designers Manage Strong Surge and Pneumatic Forces in Deep Combined Sewer Storage Tunnels." In North American Tunneling: 2010 Proceedings, 483-501. Littleton, CO: Society for Mining, Metallurgy \& Exploration.

Lewis, J. L., 2011. A Physical Investigation of Air-Water Interactions Leading to Geyser Events in Rapid Filling Pipelines. Ann Arbor, MI: University of Michigan. PhD dissertation.

Macchione, F. and M. A. Morelli. 2003. "Practical Aspects in Comparing the Shock-Capturing Schemes for Dam Break Problems." Journal of Hydraulic Engineering 129 (3): 187-95.

Vasconcelos, J. and G. Leite. 2012. "Pressure Surges Following Sudden Air Pocket Entrapment in Stormwater Tunnels." Journal of Hydraulic Engineering 138 (12).

https://doi.org/10.1061/(ASCE)HY.1943-7900.0000616

Vasconcelos, J. and S. J. Wright. 2007. “Comparison Between the Two-Component Pressure Approach and Current Transient Flow Solvers." Journal of Hydraulic Research 45 (2): 178-87.

Vasconcelos, J., S. J. Wright and P. Roe. 2006. "Improved Simulation of Flow Regime Transition in Sewers: Two-Component Pressure Approach." Journal of Hydraulic Engineering 132 (6) 553-62. 
Wright, S. J. 2013. "Influence of Air Pocket Volume on Manhole Surge." Journal of Water Management Modeling 21: R246-09. doi: 10.14796/JWMM.R246-09.
Zhou, F., F. E. Hicks and P. M. Steffler. 2002. "Transient Flow in a Rapidly Filling Horizontal Pipe Containing Trapped Air." Journal of Hydraulic Engineering 128 (6): 625-34. 